\title{
Resists and Other Critical Issues in 157-nm Lithography
}

\author{
M. Rothschild, T. M. Bloomstein, T. H. Fedynyshyn, R. R. Kunz, V. Liberman, and M. Switkes \\ Lincoln Laboratory, Massachusetts Institute of Technology \\ 244 Wood Street, Lexington, MA 02420, USA
}

\begin{abstract}
This paper outlines the critical issues facing the implementation of $157-\mathrm{nm}$ lithography as a sub-100-nm technology. Special emphasis is placed on 157-nm photoresist options, including ultrathin resists and thicker resists with new chemistries. The status of other issues is also presented, such as mask materials, pellicles, optical materials, and coatings.
\end{abstract}

Keywords: $157 \mathrm{~nm}$, photolithography, resists, pellicles

Lithography with 157-nm fluorine lasers is rapidly emerging as a viable technology for the post193-nm era [1-3]. In fact, it may become the technology of choice for the 100- to 70-nm nodes. It is attractive for several reasons, the most important being that it is fundamentally an extension of optical lithography at the longer wavelengths of 248 and $193 \mathrm{~nm}$. Therefore, it holds the promise that the toolmanufacturing and wafer-processing infrastructures can be adapted to it relatively easily, and that optical resolution enhancing techniques (phase shifting masks, off-axis illumination, etc.) can be applied to it as well. Nevertheless, the transition to the $157-\mathrm{nm}$ wavelength is by no means straightforward. It is expected to encounter difficulties that are comparable to those of earlier shifts in lithographic wavelength, from I-line to $248 \mathrm{~nm}$, and from 248 to $193 \mathrm{~nm}$. This paper summarizes the status of some of the critical issues facing $157-\mathrm{nm}$ lithography. Key among them is the development of suitable photoresists. Other technical topics include the availability of optical materials and coatings, mask materials, and pellicles, as well as ambient control to minimize contamination of optical surfaces.

The fundamental obstacle facing the development of photoresists at $157 \mathrm{~nm}$ is the high absorption coefficient of most candidate polymers [3-5]. In fact, resists that have been formulated for use at 193 and $248 \mathrm{~nm}$ are so absorptive at $157 \mathrm{~nm}$ that their practical thickness is limited to $\sim 60 \mathrm{~nm}$, assuming a maximum optical density of 0.4 . It should be pointed out that such resists may be adequate in the near term, for the purpose of evaluating the optical performance of the first generation $157-\mathrm{nm}$ exposure systems. Small-field systems are currently being fielded in several laboratories, and full-field systems are expected to be introduced within the next two years. Thus, highresolution $157-\mathrm{nm}$ resists are needed, even if, because of their thickness, they are not suitable for device fabrication.

The performance at $157 \mathrm{~nm}$ of several positive-tone 248- and 193-nm resists has been evaluated [5]. The dose-to-clear is usually significantly lower at $157 \mathrm{~nm}$ than at the design wavelength. The contrast at $157 \mathrm{~nm}$ varies, but several resists exhibit high enough contrast to make them candidates for imaging evaluation (Figure 1). Most resists do display negative-tone performance at high doses, indicating that photo-induced crosslinking takes place at this wavelength. Such effects are known to occur at longer wavelengths as well, but with significantly smaller yields. This is not surprising, in light of the high photon energy at 157 $\mathrm{nm}(7.9 \mathrm{eV})$, which may indeed induce photochemical reactions not encountered at longer wavelengths. Given the limitations outlined above, it is to be expected that resists designed for 248- or 193-nm use can be reformulated for optimized 157 $\mathrm{nm}$ use, as long as their thickness is kept below $~ 60$ nm. Indeed, we have demonstrated 157-nm patterning of a commercial $248-\mathrm{nm}$ resist and of a 
specially formulated material based on a 248-nm resist [5]. The patterning was performed in two modes: one was projection imaging with a $0.5-\mathrm{NA}$ microstepper using a binary mask, and the other was an interference system designed and built at MIT Lincoln Laboratory. Projection imaging yielded 180$\mathrm{nm}$ semi-isolated lines, with some line edge roughness (Figure 2) [5]. Interference patterning yielded $\sim 45-\mathrm{nm}$ lines and spaces, with almost no line edge roughness (Figure 3) [6]. This difference indicates that the intrinsic performance of the resist is excellent, as evidenced in the interference system, and that lens aberrations are the main reason for its degraded performance in the microstepper.

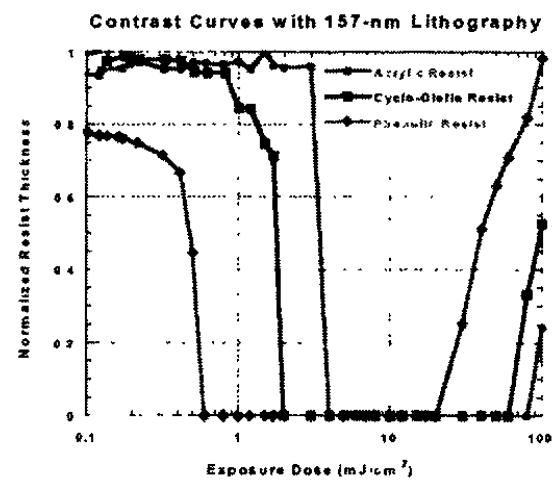

Figure 1. Comparison of contrast curves of three different classes of commercial 193 and $248 \mathrm{~nm}$ resists.

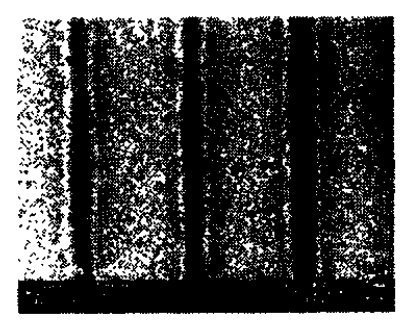

Figure 2. $157 \mathrm{~nm}$ imaging (NA $=0.50$ ) of $180 \mathrm{~nm}$ semiisolated lines of an experimental resist based on typical materials used in commercial $248 \mathrm{~nm}$ resists.

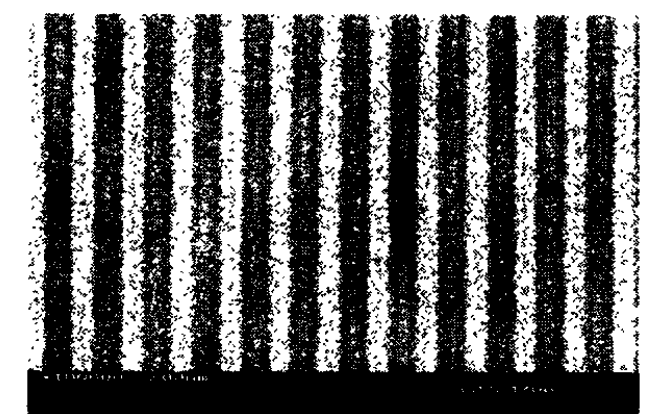

Figure 3. Scanning electron micrograph of a 50-nm-thick deep-UV resist (UV-6), exposed with the 157-nm interference lithography tool. The period is $94 \mathrm{~nm}$. Note the minimal line edge roughness.

Resists designed for device fabrication at $157 \mathrm{~nm}$ will have to overcome the thickness constraint. Several possibilities arise [4], and eventually their advantages and disadvantages will have to be balanced against each other. The first option is to stay with $60-\mathrm{nm}$ resists with excellent imageability, coupled with a hard etch mask. This adds to process complexity, but it is under consideration even for 193-nm lithography, and therefore it benefits from existing parallel process development efforts. The second possibility is the development of resists based on new, more transparent chemical platforms. The new polymers will have significantly reduced densities of $\mathrm{C}-\mathrm{H}$ bonds and carbonyl moieties, to be replaced with $\mathrm{C}$ F. The challenge here is to retain the essential chemical amplification functionality, while balancing other critical properties such as film forming, development in aqueous base, and minimal dark film loss. Significant progress in this area has been made by several groups, and more can be expected in the future [7,8]. The third option for 157 $\mathrm{nm}$ resists is at-surface imaging. Various at-surface or top-surface imaging schemes have been proposed in the past, even for 248 and $193 \mathrm{~nm}$, but almost all have encountered difficulties with line edge roughness and critical-dimension control. A significant technological breakthrough would be required to make this the preferred resist option at $157 \mathrm{~nm}$.

As mentioned above, there are several other critical issues facing 157-nm lithography. One of these, the availability of transparent mask blanks with low thermal coefficient of expansion, appears to be near resolution: fused silica with low $\mathrm{OH}$ content 
and including fluorine has been prepared by several groups $[3,9,10]$. While there are still variations in their quality, it is apparent that appropriate materials engineering can indeed yield high-transparency fused silica, which also is stable to $\sim 100$ million pulses under laser irradiation (Figure 4). On the other hand, organic pellicles that are transparent and damage resistant at $157 \mathrm{~nm}$ must still be demonstrated [3]. Recently there have been reports that such materials have indeed been engineered [11], but detailed data on damage resistance have not yet been made available. An alternative to the traditional concept of organic pellicles is the use of inorganic thin plates, possibly made of the modified fused silica that will be used as mask blank. This approach represents a significant deviation from current practice, and poses process challenges regarding thickness uniformity, control of bow, and possibly anti-reflection coating of such plates [12]. Other options that would protect masks from particulate contamination are also being considered. This area is at present an active topic of research.

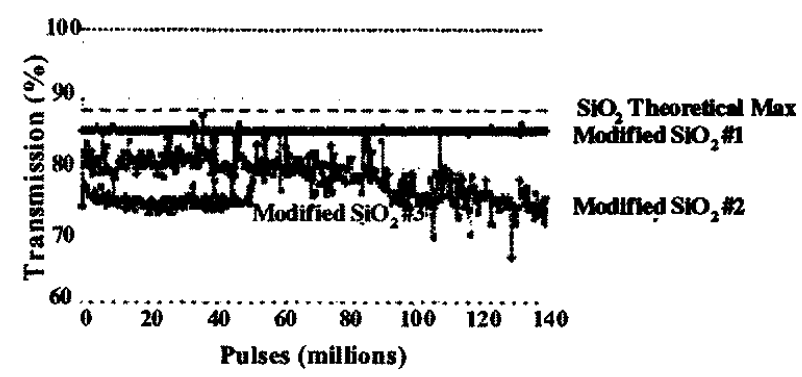

Figure 4 The transmission of three grades of modified fused silica, as measured in-situ with a $157-\mathrm{nm}$ laser. The data were normalized to the 6-mm thickness of 6-inch photomasks. The maximum theoretical transmission is also shown, based on the 157-nm index of refraction of fused silica.

Other materials-related issues at $157 \mathrm{~nm}$ are the availability of high-performance optical materials for lenses, and of appropriate optical coatings, whether anti-reflective, fully reflective, or partially reflective. The primary choice of optical lens material is crystalline calcium fluoride. Most samples tested recently appear to have low enough absorption [13], as well as excellent laser damage resistance (Figure 5). Certain optical designs of projection systems call for an extremely narrow laser linewidth $(\sim 0.1 \mathrm{pm}$, compared to the natural linewidth of $\sim 1 \mathrm{pm}$ ), or else they require a second refractive material with appropriate index dispersion properties. The main candidate for a second material is barium fluoride, but at present there is little information on its transparency and laser damage resistance at $157 \mathrm{~nm}$ [13]. Optical coatings at 157 $\mathrm{nm}$ are primarily dielectric stacks based on fluorides, such as magnesium fluoride, aluminum fluoride, etc. Few if any have met the SEMATECH target values for reflectivity or transparency. Nevertheless, it is expected that careful thin film deposition process engineering, coupled with tight control of impurities, will yield satisfactory coatings.

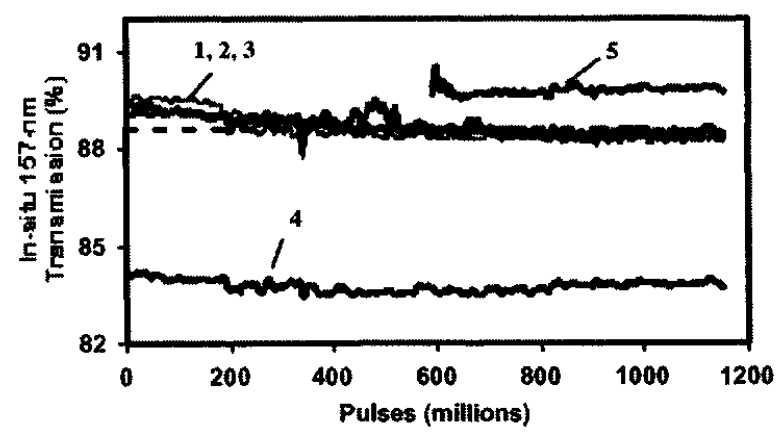

Figure 5. In-situ transmission of four 40-mm-thick different grades of $\mathrm{CaF}_{3}(1-4)$ exposed at incident fluences of $2-4 \mathrm{~mJ} / \mathrm{cm}^{2} /$ pulse. Also shown is the transmission of a 20-mm-thick reference sample (5), exposed only during the measurement cycle. The horizontal dashed line is derived from International SEMATECH targets for a $40-\mathrm{mm}$-thick $\mathrm{CaF}_{2}$ sample, assuming no surface losses except Fresnel reflection.

In summary, $157 \mathrm{~nm}$ is an active area of research, and the interest in it as a 100 - to $70-\mathrm{nm}$ technology is growing rapidly. There are still major challenges that must be overcome if it is to become a manufacturing technology within a few years. It is encouraging that no technical show-stoppers have yet been encountered, and that the overall path to improving its various aspects is understood. Nevertheless, significant progress must still be demonstrated in materials design, engineering and processing, to be followed by implementation in fullfield projection systems. 


\section{Acknowledgment}

This work was performed in part under the Advanced Lithography Program of the Defense Advanced Research Projects Agency under Air Force Contract F19628-95-C-0002, and in part under Cooperative Research and Development Agreements between MIT Lincoln Laboratory and SEMATECH and between MIT Lincoln Laboratory and Intel Corporation. Opinions, interpretations, conclusions, and recommendations are those of the authors, and do not necessarily represent the view of the United States Government.

\section{References}

1. T. M. Bloomstein, M. W. Horn, M. Rothschild, R. R. Kunz, S. T. Palmacci, and R. B. Goodman, J. Vac. Sci. Technol. B 15, 2112 (1997).

2. T. M. Bloomstein, M. Rothschild, R. R. Kunz, D. E. Hardy, R. B. Goodman, and S. T. Palmacci, J. Vac. Sci. Technol. B 16, 3154 (1998).

3. M. Rothschild, T. M. Bloomstein, J. E. Curtin, D. K. Downs, T. H. Fedynyshyn, D. E. Hardy, V. Liberman, J. H. C. Sedlacek, R. S. Uttaro, A. K. Bates, and C. Van Peski, J. Vac. Sci. Technol. $B$ 17, 3262 (1999).

4. R. R. Kunz, T. M. Bloomstein, D. E. Hardy, R. B. Goodman, D. K. Downs, and J. E. Curtin, J. Vac. Sci. Technol. B 17, 3267 (1999).
5. T. H. Fedynyshyn, R. R. Kunz, S. P. Doran, R. B. Goodman, M. L. Lind, and J. E. Curtin, to be published in the Proceedings of SPIE Microlithography 2000.

6. M. Switkes, T. M. Bloomstein, and M. Rothschild, to be published in the Proceedings of SPIE Microlithography 2000.M. Holl, to be published in the Proceedings of SPIE Microlithography 2000.

7. K. Patterson, M. Somervell, and C. G. Willson, Solid State Technology, March 2000, p. 41.

8. M. K. Crawford, A. E. Feiring, J. Feldman, R. French, M. Periysamy, F. L. Schadt, R. J. Smalley, F. C. Zumsteg, R. R. Kunz, V. Rao, and S. 9. V. Liberman, T. M. Bloomstein, M. Rothschild, J. H. C. Sedlacek, R. S. Uttaro, A. K. Bates, C. Van Peski, and K. Orvek, J. Vac. Sci. Technol. B 17, 3273 (1999).

10. M. Mizuguchi, L. Skuja, H. Hosomo, and T. Ogawa, J. Vac. Sci. Technol. B 17, 3280 (1999).

11. R. H. French et al., to be published in the Proceedings of SPIE Microlithography 2000.

12. S. Owa, in $157 \mathrm{~nm}$ Technical Review (Waltham, MA, Novermber 17-19, 1999, organized by International SEMATECH), pp. 337-352.

13. V. Liberman, M. Rothschild, J. H. C. Sedlacek, R. S. Uttaro, A. K. Bates, C. Van Peski, and $\mathrm{K}$. Orvek, to be published in the Proceedings of SPIE Microlithography 2000. 